\title{
Numerical simulations of radar rainfall error propagation
}

\author{
Hatim O. Sharif ${ }^{1}$ and Fred L. Ogden \\ Department of Civil and Environmental Engineering, University of Connecticut, Storrs, Connecticut, USA
}

Witold F. Krajewski

IIHR/Hydroscience and Engineering, University of Iowa, Iowa City, Iowa, USA

\author{
Ming Xue \\ Center for Analysis and Prediction of Storms and School of Meteorology, University of Oklahoma \\ Norman, Oklahoma, USA
}

Received 20 March 2001; revised 21 November 2001; accepted 21 November 2001; published 13 August 2002.

[1] The primary advantage of radar observations of precipitation compared with traditional rain gauge measurements is their high spatial and temporal resolution and large areal coverage. Unfortunately, radar data require vigorous quality control before being converted into precipitation products that can be used as input to hydrologic models. In this study we coupled a physically based atmospheric model of convective rainfall with an active microwave radiative transfer model to simulate radar observation of thunderstorms. We used the atmospheric model to simulate a well-documented tornadic supercell storm that occurred near Del City, Oklahoma, on 20 May 1977. We then generated radar observations of that storm and used them to evaluate the propagation of radar rainfall errors through distributed hydrologic simulations. This physically based methodology allows us to directly examine the impact of radar rainfall estimation errors on land-surface hydrologic predictions and to avoid the limitations imposed by the use of rain gauge data. Results indicate that the geometry of the radar beam and coordinate transformations, due to radar-watershed-storm orientation, have an effect on radar rainfall estimation and runoff prediction errors. In addition to uncertainty in the radar reflectivity versus rainfall intensity relationship, there are significant range-dependent and orientation-related radar rainfall estimation errors that should be quantified in terms of their impact on runoff predictions. Our methodology provides a tool for performing experiments that address some operational issues related to the process of radar rainfall estimation and its uses in hydrologic prediction. INDEX TERMS: 1854 Hydrology: Precipitation (3354); 1860 Hydrology: Runoff and streamflow; 1894 Hydrology: Instruments and techniques; 3210 Mathematical Geophysics: Modeling; KEYWORDS: modeling, watershed, simulation, radar rainfall, surface runoff, uncertainty propagation

\section{Introduction}

[2] The performance of distributed, physically based hydrologic models depends greatly on the quality of the input data. The most important input is rainfall because such models are very sensitive to it [Julien and Moglen, 1990], particularly models of Hortonian [Horton, 1933] runoff. Errors in the space-time description of rainfall are often amplified through Hortonian runoff predictions [Ogden and Sharif, 2000]. The shortcomings of rain gauge networks are well documented. Rain gauges do not represent areal rainfall at the watershed scale well because they are merely point samples, while watersheds are sensitive to the spatial distribution of rainfall. The use of rain gauge data necessitates spatial interpolation of the rainfall data. The accuracy

\footnotetext{
${ }^{1}$ Now at National Center for Atmospheric Research, Research Applications Program, Boulder, Colorado, USA.

Copyright 2002 by the American Geophysical Union. 0043-1397/02/2001WR000525\$09.00
}

of the resultant rainfall fields is limited by the correlation structure of rainfall and the network density.

[3] The primary advantage of radar precipitation products is their high spatial and temporal resolution and large areal coverage. Severe flood and flash flood forecasting [Georgakakos, 1986a, 1986b] and urban storm runoff modeling [Ogden et al., 2000] require high-resolution precipitation data. Early assessments of the usefulness of radar rainfall estimation errors in flow forecasts [e.g., Barge et al., 1979] were optimistic. However, more recent studies have shown that the impact of radar rainfall estimation errors on runoff predictions can be very significant in certain situations.

[4] The National Weather Service (NWS) has updated its weather radar capabilities with the deployment of over 120 WSR-88D (Weather Surveillance Radar, 1988-Doppler) radars. The WSR-88D radar network provides the 48 contiguous United States with nearly continuous radar coverage below $3000 \mathrm{~m}$ above sea level, except where rising terrain occludes low elevation angle scans. The WSR-88D system represents a significant advance in the field of operational hydrology over older technology. 
The system provides a large number of diverse hydrometeorological products [Fulton et al., 1998].

[5] Unfortunately, there are no unique relationships between the radar-measured reflectivity and the rainfall rate. The relationship between radar reflectivity and surface rainfall is highly complex [Austin, 1987]. In addition to the difficulties in estimating the parameters of this relationship, there are many other physical factors that increase the uncertainty of radar rainfall estimation. Radar rainfall estimates are always at risk of being contaminated by a host of random and systematic error sources. Some of the other potential sources of errors are radar hardware calibration, the deflection of the radar beam from its path (anomalous propagation), the attenuation of the electromagnetic wave by rain and atmospheric gases, the presence of frozen hydrometeors and the melting layer, and range effects. A discussion of numerous sources of radar rainfall estimation error is given by Wilson and Brandes [1979], Zawadzki [1982, 1984], and Krajewski and Smith [1991].

[6] The need to improve hydrologic predictions indicates the increased importance of research efforts in the dynamic numerical modeling of quantitative precipitation, either through explicit treatment or through parameterization. The dynamic (physically based) models of rainfall are usually based on sets of partial differential equations, which describe conservation of mass, momentum, and energy in the atmosphere. Subgrid-scale physics are parameterized using grid-scale variables. These equations are integrated numerically in time in a three-dimensional model domain to produce predictions of rainfall, in addition to a complete set of state variables. The past two decades have seen increased usage of explicit cloud models in the simulation and prediction of convective storms [e.g., Klemp et al., 1981; Droegemeier et al., 1996; Xue et al., 1996a, 1996b]. Significant progress has been made in the use of radar observations to initialize real storms and produce realistic forecasts of intense precipitation systems [e.g., Lin et al., 1993; Shapiro et al., 1996; Gao et al., 1998; Sun and Crook, 1998; Grecu and Krajewski, 2000a, 2000b]. Numerical, physically based modeling of storms facilitates our understanding of the three-dimensional variability of hydrometeor characteristics. When modeled storms are coupled with a scheme for simulating the physics of electromagnetic wave propagation, the simulation system provides an opportunity to study some aspects of the complex relationship between radar observables and the true (although simulated) rainfall fields and the impacts of radar rainfall estimation errors on runoff predictions.

\section{Objectives}

[7] In this paper we use a simulation methodology to examine the propagation of radar rainfall estimation errors, due to a variety of causes, through Hortonian runoff predictions. We use an atmospheric model to generate convective storms and an active microwave radiative transfer model to simulate the propagation of electromagnetic waves between the radar and the storms. This methodology allows us to assume that the rainfall fields generated by the atmospheric model are the "truth." We use radar-estimated rainfall from simulated storms as input to a calibrated (for a certain actual basin), physically based, infiltration excess, watershed model to study the propagation of radar rainfall estimation errors. In addition to the influence of radar range and radar orientation, we impose systematic and random errors on the radar estimation process to study their impact on runoff prediction. Our simulation methodology allows us to avoid the traditional approach of assessing radar estimate accuracy by comparisons with rain gauges, which is subject to several fundamental limitations [Zawadzki, 1975; Ciach and Krajewski, 1999]. Furthermore, we simulate the radar estimation process below the freezing level to avoid the complex ice microphysics and "bright band" effects. We also analyze the effect of adjusting radar rainfall estimates on predicted runoff.

\section{The Tools}

\subsection{The Atmospheric Model}

[8] The Advanced Regional Prediction System (ARPS) is a general purpose, nonhydrostatic, compressible model for storm-scale and mesoscale atmospheric simulation and realtime numerical weather prediction [Xue et al., 1995; Xue et al., 2000, 2001]. The model was developed at the Center for Analysis and Prediction of Storms (CAPS) at the University of Oklahoma, with the support of the National Science Foundation Science and Technology Center (STC) program. The model solves equations for momentum, temperature, pressure, water substances, and subgrid-scale turbulent kinetic energy and includes comprehensive physical processes. The model serves as an effective tool both for basic research and for operational numerical weather prediction [e.g., Droegemeier et al., 1996; Xue et al., 1996b]. Additional examples of the model applications are given by Xue et al. [2000, 2001].

\subsection{The Radar Simulator}

[9] Krajewski et al. [1993] proposed a physically based simulation of radar observations based on a two-dimensional stochastic space-time model of rainfall events and a statistically generated drop-size distribution. Anagnostou and Krajewski [1997] made several extensions to this simulator. The two-dimensional fields were complemented with a vertical structure of hydrometeors by choosing a cloud type model, which resulted in size, shape, and phase (mixed or single) distribution at discrete elevations. Recently, Anagnostou and Morales [2000] used the simulator in their study of Next Generation Weather Radar (NEXRAD) calibration based on a comparison with the Tropical Rainfall Measuring Mission (TRMM) satellite [Kummerow et al., 1998].

[10] We modify the radar simulator in this study to calculate various radar observables from the three-dimensional output produced by the ARPS atmospheric model. We modify the beam geometry to capture the high variability within convective systems. The simulator extracts three-dimensional estimates of pressure, temperature, cloud rainwater content, and water vapor content from ARPS and uses these outputs to calculate the mixing ratios of rainwater and the gradients of the atmospheric refractive index. We simulate beam propagation in a three-dimensional space. The simulated radar measurement process includes integrating over the pulse volume using a Gaussian beam power distribution. We use the default WSR-88D $Z-R$ relationship of $Z=300 R^{1.4}$, where $Z$ is the equivalent radar reflectivity 
factor, in $\mathrm{mm}^{6} / \mathrm{m}^{3}$, and $R$ is the rainfall rate, in $\mathrm{mm} / \mathrm{hr}$ [Fulton et al., 1998], to convert reflectivities into rainfall rate estimates. The radar wavelength is assumed to be 10 $\mathrm{cm}$, the beam elevation angle is $0.5^{\circ}$, and the half-power beam width is $1^{\circ}$, close to WSR-88D's value of $0.95^{\circ}$. The azimuthal resolution of radar observations is $1^{\circ}$.

\subsection{The Hydrologic Model}

[11] The hydrologic model used in this study is the physically based, distributed parameter, Hortonian, finite difference model CASC2D (cascade of planes, two-dimensional) [Julien et al., 1995; Ogden, 1998]. The model accepts fully spatially varied rainfall input, uses Green and Ampt [1911] infiltration with redistribution [Ogden and Saghafian, 1997], two-dimensional diffusive-wave overland flow routing, and one-dimensional diffusive-wave channel routing. CASC2D has the capability to model a variety of channel cross sections [Ogden, 1994] and includes continuous soil moisture accounting [Ogden and Senarath, 1997; Senarath et al., 2000]. The model was also used in a flash flood simulation study in which perennial and ephemeral lakes were modeled [Ogden et al., 2000]. The model uses a square grid representation of the watershed at a user-selected grid size. Once ponding occurs, surface water is accumulated in each model grid cell until the specified retention depth for that cell is exceeded. Thereafter the overland flow is routed into two orthogonal directions. When overland flow reaches a model grid cell that contains a defined channel, the flow is passed into the channel and routed using a one-dimensional explicit diffusive-wave routine. The theory, development, and applicability of CASC2D are discussed at length by Downer et al. [2002].

\section{The Study Watershed}

[12] The watershed used in this study for hydrologic simulations is the $21.2 \mathrm{~km}^{2}$ Goodwin Creek Experimental Watershed located in north central Mississippi. The USDAARS National Sedimentation Laboratory has continuously monitored the watershed since 1981. Alonso [1996] provides a detailed description of the watershed. The elevation of the watershed ranges from 68 to $127 \mathrm{~m}$. The main channel has an average slope of 0.004 [Bingner, 1996]. The grid size used in CASC2D to model the watershed is $125 \times 125 \mathrm{~m}$, to minimize computing time yet adequately describe the spatial variability of topography, soil texture, and land use/land cover. Hortonian runoff is dominant and the contribution of groundwater to runoff is insignificant in the watershed. The groundwater table is several meters below surface; according to measurements, it varies by only $5-10 \mathrm{~cm}$ near channels during significant runoff events. The base flow at the outlet of the catchment is typically below $0.05 \mathrm{~m}^{3} \mathrm{~s}^{-1}$. The hydrologic model CASC2D was rigorously calibrated on this watershed by Senarath et al. [2000], and thus we feel the model represents the watershed's runoff processes with reasonable accuracy.

\section{Numerical Framework}

\subsection{ARPS Simulations}

[13] Within the framework of this methodology, we simulate a well-documented tornadic supercell storm that occurred near Del City, Oklahoma, on 20 May 1977 using the ARPS. This storm has been studied extensively using both multiple Doppler radar analysis and numerical simulation. For details on storm morphology and evolution, the readers are referred to Ray et al. [1981] and Klemp et al. [1981].

[14] We simulate 2 hours of the storm's total duration. The simulation starts from a thermal bubble placed in a horizontally homogeneous base state, specified from the sounding used by Klemp et al. [1981]. Like Klemp et al. [1981], we subtract a wind vector of $U=3 \mathrm{~m} \mathrm{~s}^{-1}$ and $V=14 \mathrm{~m} \mathrm{~s}^{-1}$ from the wind profile of the environmental sounding to keep the right moving storm near the center of the model domain. Effectively, we are using a computational domain that translates in space at a velocity of $(3,14) \mathrm{m} \mathrm{s}^{-1}$; in other words, we are simulating the storm in a moving reference frame.

[15] The model grid consists of $67 \times 67 \times 35$ grid points with a uniform grid interval of $1 \mathrm{~km}$ in the horizontal and $0.5 \mathrm{~km}$ in the vertical direction. The physical domain size is therefore $64 \times 64 \times 16 \mathrm{~km}^{3}$. The initial bubble was centered at $x=48 \mathrm{~km}, y=16 \mathrm{~km}$, and $z=1.5 \mathrm{~km}$ and has a maximum perturbation temperature of $4 \mathrm{~K}$. The radius of the bubble is $10 \mathrm{~km}$ in both the $x$ and $y$ directions and $1.5 \mathrm{~km}$ in the vertical. We use the Kessler [1969] warm rain microphysics option together with a 1.5-order turbulent kinetic energy subgrid turbulence parameterization. We also use open boundary conditions at the lateral boundaries and an upper level Rayleigh damping layer.

[16] Between 30 and 60 min the simulated storm underwent a splitting process (Figure 1, top panels), with the right moving (relative to the environmental wind shear vector, which points in the northeast direction) cell remaining near the center of the domain, and the left moving cell propagating to the northwest corner of the domain. The precipitation rates from the simulated storm at 30-min intervals are shown in Figure 1 (only three quarters of the simulation domain in terms of the length of each side is shown), corresponding to $30,60,90$, and $120 \mathrm{~min}$ after initiation of the storm. The use of a moving coordinate system (through the deduction of a mean wind) makes the simulated storm, especially the right moving cell, appear roughly stationary relative to the grid. Relative to the ground, this right moving cell moves at a speed of about $14.3 \mathrm{~m} \mathrm{~s}^{-1}$ in a north-northeast direction, as given by the velocity vector $(3,14) \mathrm{m} \mathrm{s}^{-1}$. The domain translation vector is shown in Figure 1.

[17] The patterns of the surface precipitation rate usually resemble the pattern of radar reflectivity fields. The hookshaped pattern associated with the right moving cell is also associated with the so-called hook echoes that demonstrate the strong rotation associated with tornadic supercell thunderstorms. In this simulation the left moving cell is actually stronger (Figure 1, bottom left panel). The evolution of the simulated storm is qualitatively similar to the observed storm [Ray et al., 1981], and after 2 hours, it has attained a structure typical of mature supercell storms.

[18] We show a sample of some randomly selected instantaneous vertical reflectivity profiles that we compute using the storm hydrometeor fields in Figure 2. The solid line represents the mean reflectivity profile of all samples measured at all ARPS grids for the entire simulated time period. The reflectivity profiles, including the mean, are similar to the profiles reported in the literature [e.g., Szoke 

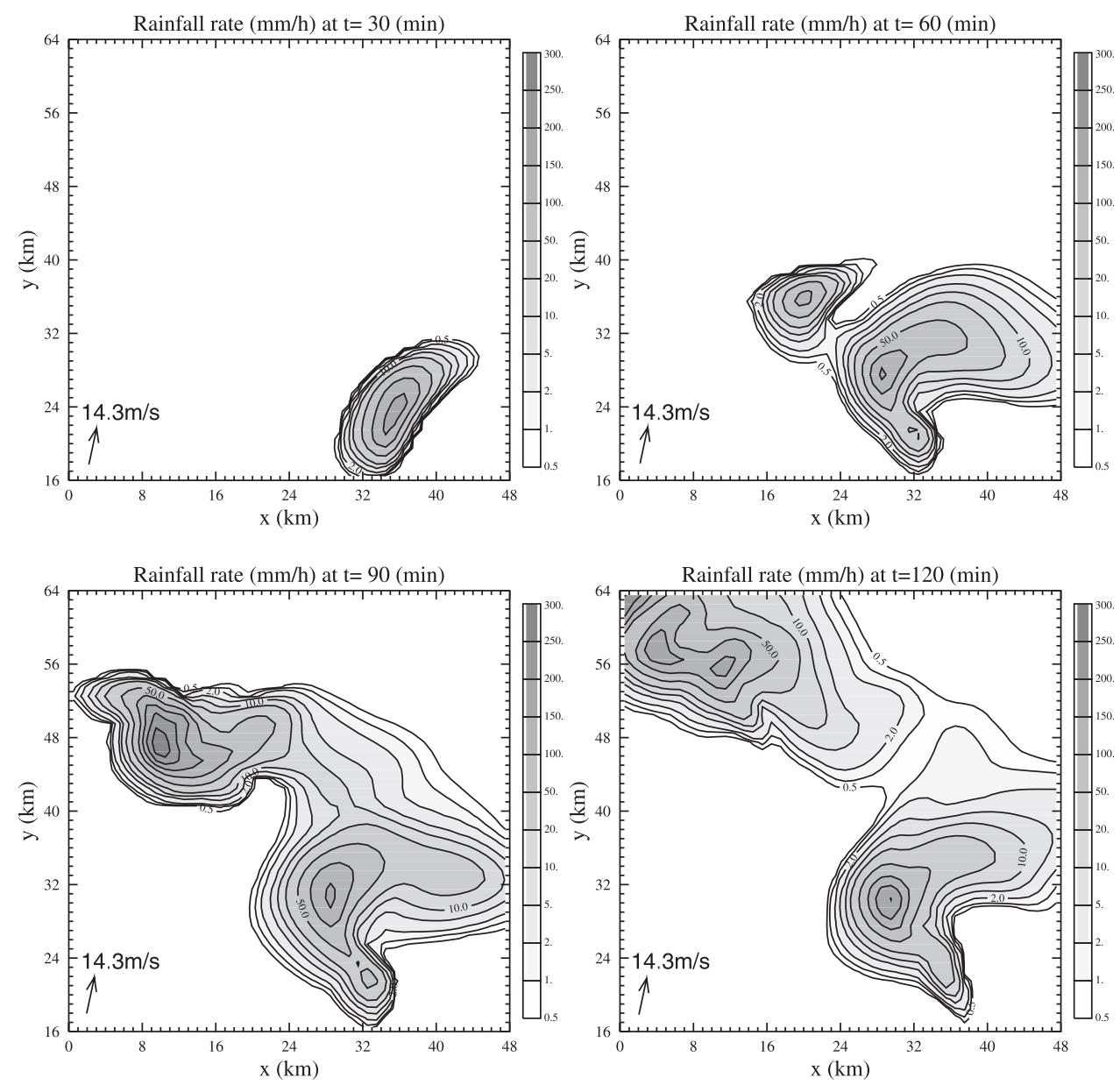

Figure 1. Instantaneous rain fall rates $\left(\mathrm{mm} \mathrm{h}^{-1}\right)$ from the ARPS simulated 7 May 1977 Del City, Oklahoma, supercell storm, at 30,60, 90, and 120 min of simulation. Only a portion of the $64 \times 64 \mathrm{~km}^{2}$ model domain is shown, as indicated by the axis labels. The direction of the domain translation is indicated by an arrow in each plot, and the speeds are $3 \mathrm{~m} \mathrm{~s}^{-1}$ and $14 \mathrm{~m} \mathrm{~s}^{-1}$ in the east-west and northsouth directions, respectively.

et al., 1986a, 1986b] and the profiles from the WSR-88D data [Vignal and Krajewski, 2001]. The spatial correlation within the storm, and the fractional areal coverage of the storm based on rainfall intensity, computed at a certain snapshot during the storm evolution (Figures $2 \mathrm{~b}$ and $2 \mathrm{c}$ ), are similar to some of those found in the literature [e.g., Calheiros, 1984]. This similarity also indicates that ARPS output is reasonably representative of a convective storm.

\subsection{Radar-Storm Watershed Orientation}

[19] Since radar beams rise and widen with range, the radar-viewing aspect of a storm may have an effect on the radar estimates for a highly variable three-dimensional convective cell. Different orientations result in different coordinate geometry and volumetric averaging of radar observables. To investigate these effects quantitatively, we place our virtual radar at 24 equally spaced orientations (every $15^{\circ}$ ). We also vary the range along these directions as illustrated in Figure 3. Since the storm domain is significantly larger than the study watershed, we vary the watershed location within the storm. Because of the high variability within the convective storm, we move the watershed to 10 different locations within the storm domain to obtain different cases of the radar estimation process. The ten locations do not overlap and are sufficiently far apart from each other to be considered independent storm realizations.

[20] We assume the hydrographs simulated using CASC2D, driven by the "true" ARPS rainfall fields, are the true runoff hydrographs. We use four measures for comparing these true-rainfall-based simulations with the ones based on radar estimates: the watershed total rainfall volume ratio, the root-mean-square error in the simulated hydrograph, the total runoff volume ratio, and the peak discharge ratio.

[21] In addition to the effects of range and orientation, we also studied the effects of both systematic and random errors. Random errors resulting from the uncertainty in the relationship between the radar reflectivity and the rainwater mixing ratio, or radar system noise, and additive calibration drifts, were imposed to study their impact. The simulator computes radar observables using either a constant value for the slope of the refractive index or a value calculated from atmospheric variables to study the impact on the hydrologic model output. We compute the attenuation of electromagnetic waves by rain as a function of the radar wavelength 

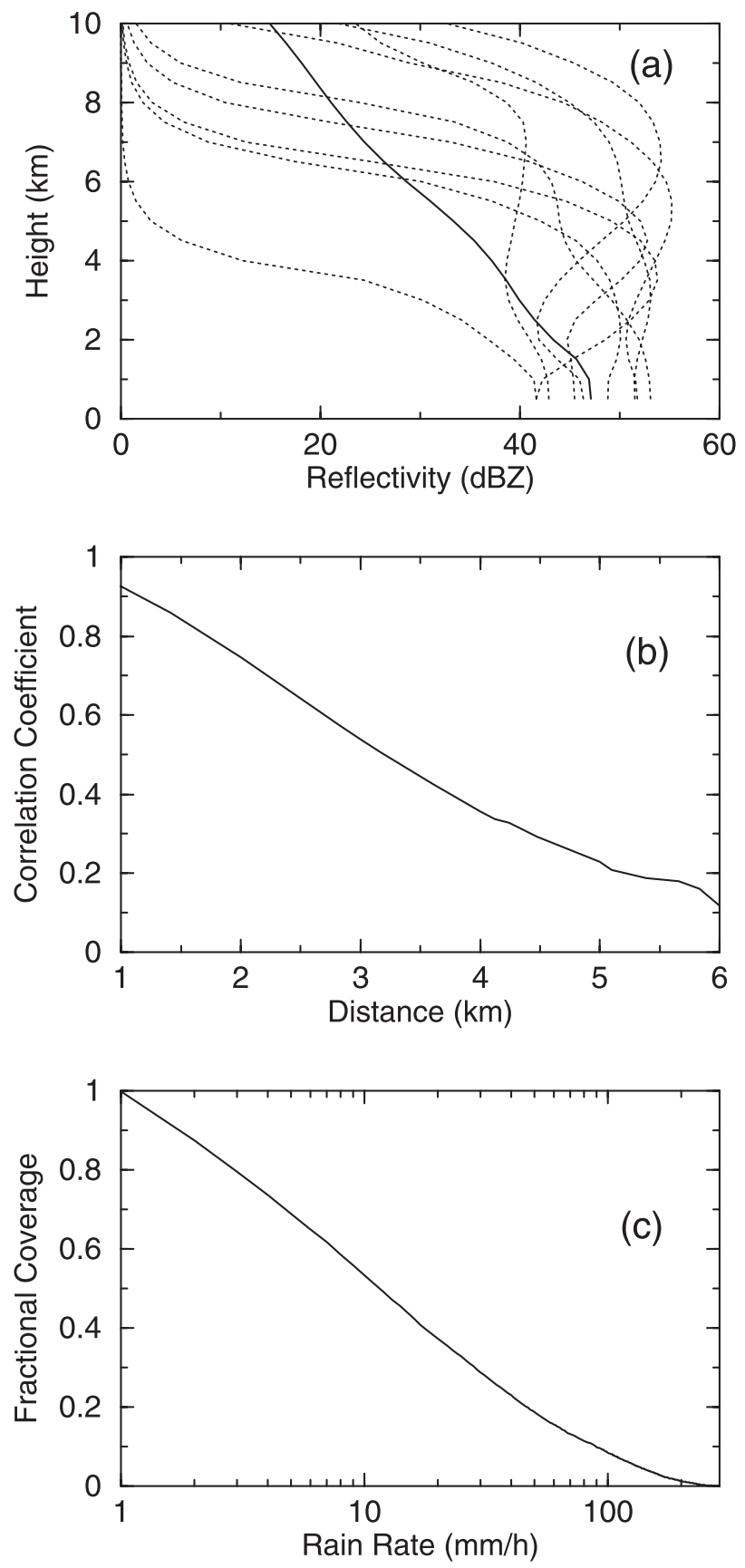

Figure 2. Characteristics of the ARPS simulated storm: (a) random samples from reflectivity profiles at different locations and times; (b) spatial correlation of the rainfall field; and (c) fractional coverage of different rainfall intensities. The bold line in Figure $2 \mathrm{a}$ is the storm total average reflectivity profile.

$(10 \mathrm{~cm})$, rainfall intensity, and the distance between the radar and the hydrometeors. The attenuation from atmospheric gases, which is typically larger than rain attenuation for $\mathrm{S}$ band, is only a function of radar wavelength and distance [Doviak and Zrnic, 1993]. We do not model atmospheric gas attenuation because this effect is taken care of in real radar data processing systems.

[22] Finally, after computing the radar-estimated total rainfall volume over the basin, $V_{r}$, we compare it to the true total rainfall volume, $V_{t}$, and find the ratio of the two volumes, $V_{t} / V_{r}$. We then multiply all instantaneous radar rainfall estimates by that ratio, or "storm total bias," such that the watershed total rainfall volume is equal to the true watershed total rainfall volume, for all ranges and orientations (see a similar bias adjustment approach by Smith et al. [1996a]). We compare the resulting outputs of the hydrologic model, using these adjusted radar estimates, to the true hydrologic outputs. This is done to assess the quality of the hydrologic outputs driven by adjusted radar rainfall estimates.

\section{Results}

\subsection{Simulations With No Imposed Errors}

[23] In the first part of this study we assume that the simulated radar measurement process is error-free to study the pure effects of range and orientation between the radar and the study watershed. The closest radar position we test is $10 \mathrm{~km}$ from the center of the watershed. We then gradually increase the range at increments of $5 \mathrm{~km}$, out to a maximum range of $145 \mathrm{~km}$ from the center of the watershed. We limit the range to $145 \mathrm{~km}$ in order to avoid the influence of the freezing level on the radar-measured reflectivity for the storm being studied. In a few instances the simulated radar beam intersected the freezing level at far range. However, since warm-rain processes were assumed in the ARPS simulations, the simulated beam intersected the freezing level very infrequently.

[24] To quantify the effects of radar orientation, we place the radar at 24 equally spaced orientations (every $15^{\circ}$ ), and vary the range in these directions, as illustrated in Figure 3. The range increments start $10 \mathrm{~km}$ from the watershed center, are spaced $5 \mathrm{~km}$ apart out to $145 \mathrm{~km}$, and are the same for all 24 radar orientations. The orientations are coded with numbers 1 through 24 , orientation 1 being

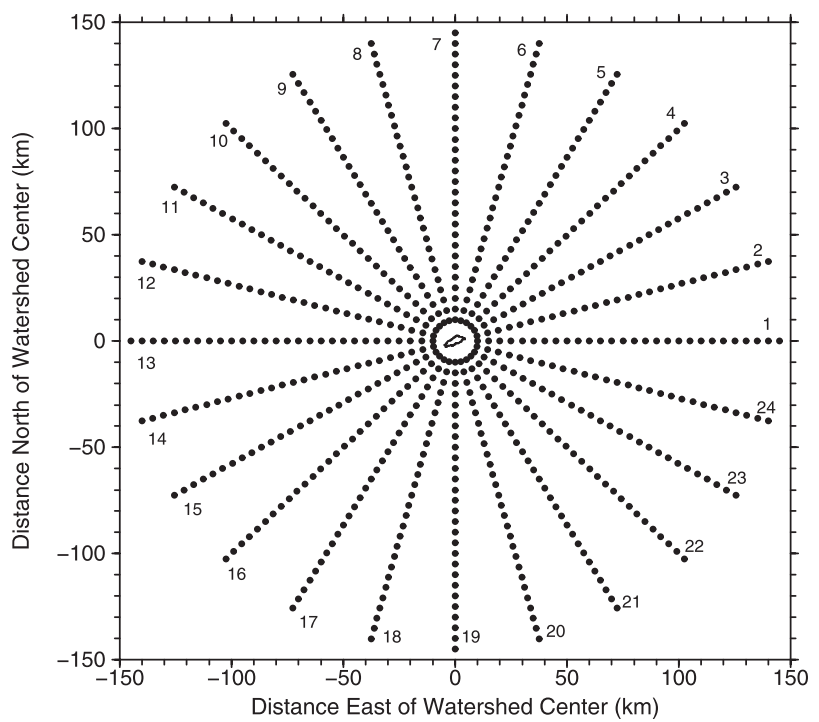

Figure 3. Configuration of the simulated radar orientations around Goodwin Creek. The radar range is varied along these orientations. The outline of the $21.2 \mathrm{~km}^{2}$ Goodwin Creek Experimental Watershed is shown at the origin of the figure. 

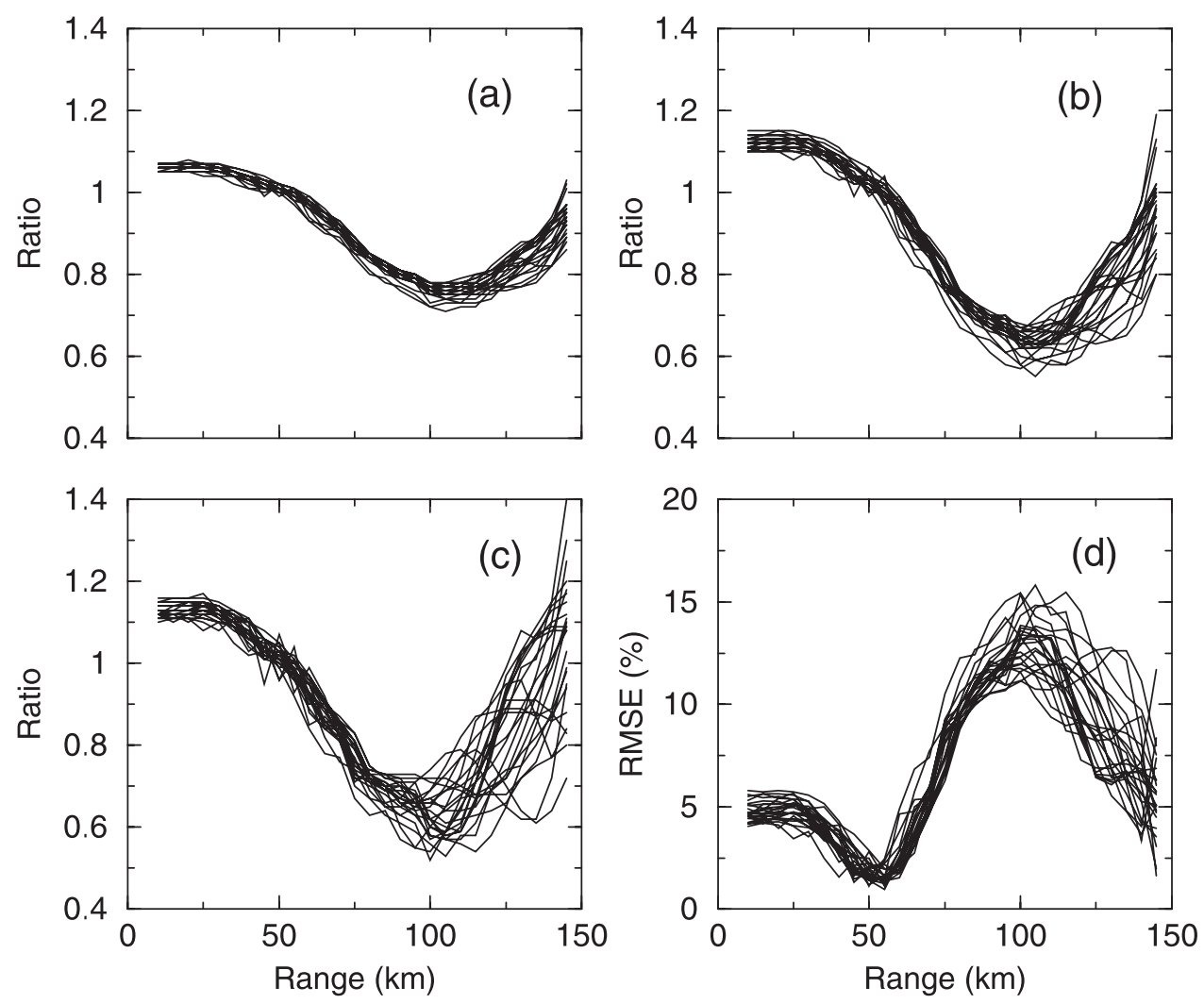

Figure 4. Measure of the effects of radar range/orientation on the estimated rainfall volume and hydrograph, with curves corresponding to 24 different radar orientations (see Figure 3): (a) ratio of radarestimated rainfall volume and 'true' rainfall volume; (b) ratio of radar-based runoff volume and true runoff volume; (c) ratio of radar-based peak discharge and true peak discharge; and (d) radar-based hydrograph root-mean-square error expressed as a percentage of the true peak discharge. The graphs are for watershed location 3 in Table 1.

exactly east of the watershed center. We distribute the orientations over $360^{\circ}$ because of the asymmetry of the simulated storm and watershed. Radar rainfall estimates are entered into the hydrologic model in polar coordinates. Because the hydrologic model grids are smaller $(125 \mathrm{~m})$ than the radar bins $\left(1^{\circ} \times 1^{\circ} \times 1 \mathrm{~km}\right)$, we apply the nearestneighbor method to assign rainfall rates to each hydrologic model grid. We did not perform any vertical interpolation of rainfall below the beam in these simulations.

[25] The rainfall volume error measure is the ratio between the radar-estimated catchment total rainfall volume and the true total rainfall volume predicted at the ground level by the atmospheric model. The error statistics of the influence of radar error on hydrologic model response used in this study are three of the statistics that are typically used to calibrate hydrologic models and evaluate their performance [e.g., Brazil, 1988; Senarath et al., 2000]. Root-meansquare hydrograph error (RMSE) is computed using

$$
\mathrm{RMSE}=\sqrt{\frac{1}{2} \sum_{i=1}^{N}\left(q_{i}^{\mathrm{est}}-q_{i}^{\mathrm{ref}}\right)^{2}}
$$

where $q^{\text {est }}$ is the simulated discharge driven by radarestimated rainfall and $q^{\text {ref }}$ is the corresponding discharge resulting from the reference ARPS modeled rainfall (i.e., we assume the hydrograph produced using ARPS rainfall fields to be the reference hydrograph). $N$ refers to the total number of hydrograph ordinates used in the analysis, while $i$ is the index denoting individual hydrograph ordinates. RMSE is expressed as a percentage of the reference peak discharge.

[26] The error in peak discharge is expressed as the ratio between the estimated peak discharge and the true peak discharge. The error in runoff volume is similarly expressed as the ratio of the estimated and reference total runoff volumes. All these error statistics are based on the total storm volumes and maximum discharge and represent the average trend.

\subsection{Effects Of Range/Orientation}

[27] We show the combined effects of range and orientation on the estimated rainfall field in Figure 4a. These are the results from a set of simulations with the watershed at one of the 10 locations tested within the storm domain. Each curve in the graph represents one of the radar orientations. The effect of range is clear on all 24 lines, and the scatter resulting from orientation effect is significant. The scatter is very small at the $10-\mathrm{km}$ range and increases steadily with range. The largest scatter occurs when the radar is $145 \mathrm{~km}$ from the center of the watershed, the farthest range we tested. The scatter varies from $2 \%$ to about $17 \%$ of the total rainfall volume. In all the plots of Figure 4, curves adjacent to each other generally represent orientations that are close 

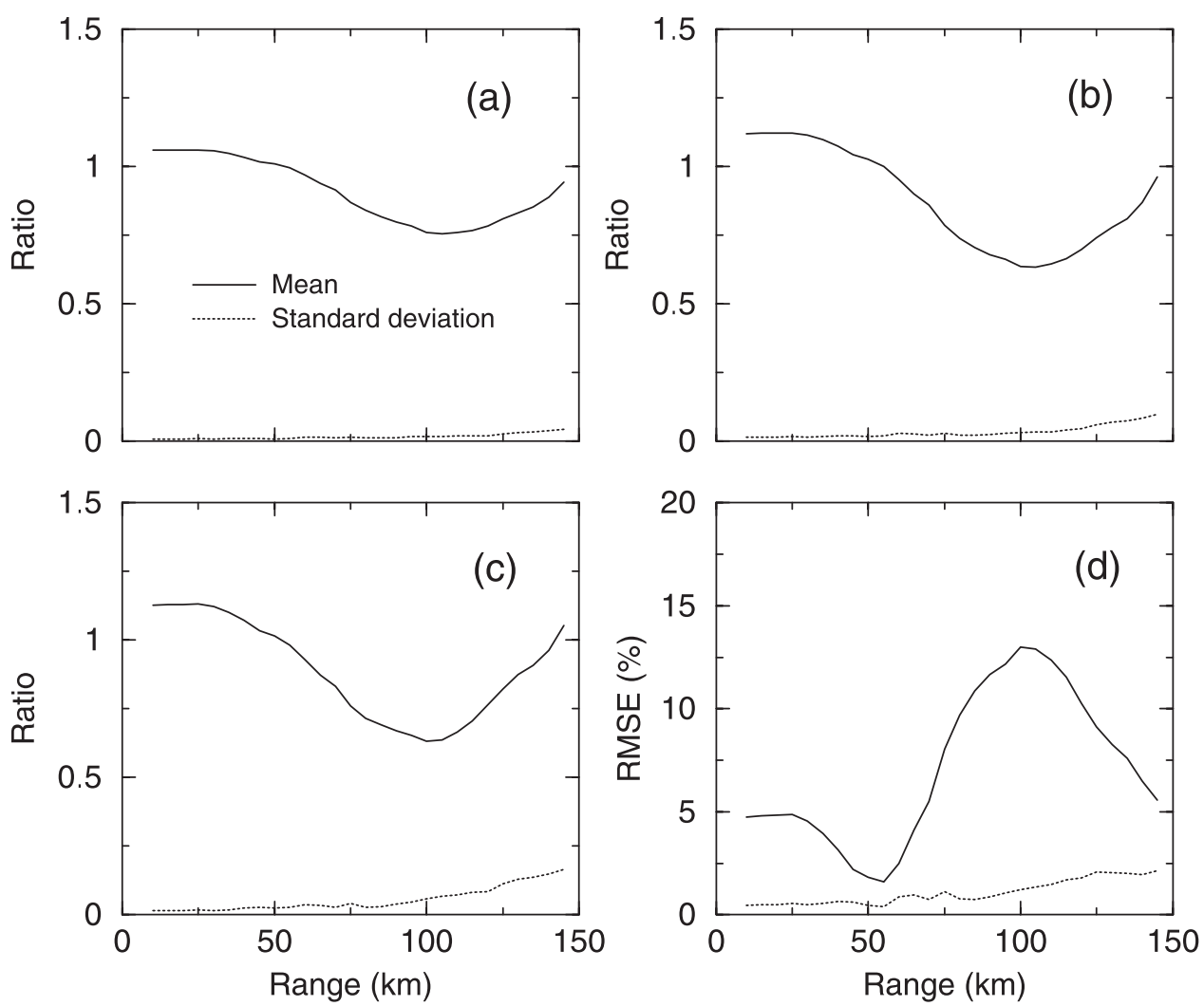

Figure 5. Average (solid lines) and standard deviation (dotted lines) of the 24 curves shown in Figure 4.

together; for example, in Figure 4a the line representing orientation 7 is adjacent to the line representing orientation 6. Lines representing orientations $180^{\circ}$ apart are generally adjacent to each other for small ranges and start to diverge with increasing range. Most of the 24 lines follow a distinct pattern, which is a gradual decrease with increasing range to about $100-110 \mathrm{~km}$, followed by a more rapid increase with increasing range. This is clear in Figure 5a, which shows the mean for the 24 orientations. The maximum average rainfall volume error is $24 \%$ at a range of about $100 \mathrm{~km}$. The standard deviation of the 24 rainfall volume ratios increases almost linearly with range, as seen in Figure 5a. The response to the combined effect of range and orientation is similar for the other nine watershed locations.

[28] The error in the predicted runoff is somewhat different. Radar rainfall estimation errors are generally amplified through predicted runoff. The variance in predicted runoff volume is more than double that for the rainfall volume, as shown in Figure $4 \mathrm{~b}$. The average value of runoff volume error, shown in Figure $5 \mathrm{~b}$, whether from underestimation or overestimation, is twice the average rainfall volume error (Figure 5a) even though the curves in both graphs follow a similar trend. The standard deviation of the 24 runoff volume ratios, shown in Figure $5 \mathrm{~b}$, is about twice that of rainfall volume ratios, and the increase with range is similar to that of the rainfall volume curve. The runoff simulations show that both range and orientation errors are amplified in the predicted runoff. The graphs representing the error in peak discharge (Figure 4c) are similar to runoff volume error graphs. Interestingly, for some orientations there is no significant change in the peak discharge error after the range of 100-110 km
(Figure 4c), which suggests that rainfall volume errors are compensated for by other errors. The graph of the hydrograph root-mean-square error (RMSE), shown in Figure $4 d$, has a linear-convex-concave shape. The linear portion corresponds to the region where the rainfall (or runoff) is overestimated. This part shows a small change with range. The convex portion of the curve corresponds to the region where overestimation decreases and underestimation starts. The curve becomes concave as the underestimation continues with range, and the slope changes sign as the underestimation begins to decrease. The scatter due to orientation increases with range, but the general pattern is different from other graphs, because the RMSE does not differentiate between underestimation and overestimation.

[29] We summarize rainfall and runoff statistics from ARPS simulations for the 10 watershed locations in Table 1 and summarize the average values of error statistics in Figure 6. The mean rainfall volume error curves (Figure 6a) show a different trend because each location represents an independent realization of the storm. The curve showing the highest error corresponds to the watershed location with the smallest total rainfall accumulation (location 6 in Table 1). The watershed response depends largely on the rainfall error and also on the magnitude of the rainfall volume and the spatial distribution of the rainfall (Figure $6 \mathrm{~b}$ and $6 \mathrm{c}$ ). The increase of RMSE with range is drastic for the location with the smallest rainfall accumulation (Figure 6d). For two locations, RMSE decreases with range. At these two locations, with some of the highest rainfall accumulations, the estimated rainfall volume on the watershed is smaller than the true rainfall volume and increases slightly with range. 
Table 1. Rainfall and Runoff Statistics, $x-y$ Coordinates, and Mean Storm Velocity Vectors for the 10 Watershed Locations ${ }^{\mathrm{a}}$

\begin{tabular}{ccccccc}
\hline $\begin{array}{l}\text { Watershed } \\
\text { Location }\end{array}$ & $\begin{array}{c}\text { ARPS Rainfall } \\
\text { Volume, } \mathrm{m}^{3}\end{array}$ & $\begin{array}{c}\text { Peak } \\
\text { Discharge, } \mathrm{m}^{3}\end{array}$ & $\begin{array}{c}\text { Runoff } \\
\text { Volume, } \mathrm{m}^{3}\end{array}$ & $\begin{array}{c}\text { Runoff Production } \\
\text { Efficiency }\end{array}$ & $\begin{array}{c}x, y \text { Coordinates } \\
\text { of Watershed } \\
\text { Location, km }\end{array}$ & $\begin{array}{c}x, y \text { Components of } \\
\text { Mean Storm Velocity } \\
\text { Vector, } \mathrm{m} \mathrm{s}^{-1}\end{array}$ \\
\hline 1 & $1,287,741$ & 104.8 & 766,884 & 0.60 & 42,49 & 1,2 \\
2 & $1,230,439$ & 103.7 & 688,193 & 0.56 & 52,47 & 1,2 \\
3 & 803,040 & 56.7 & 363,803 & 0.45 & 44,36 & 1,1 \\
4 & 828,942 & 59.2 & 390,689 & 0.47 & 53,37 & 1,2 \\
5 & 689,706 & 45.6 & 316,993 & 0.46 & 58,27 & 1,1 \\
6 & 450,961 & 13.5 & 124,478 & 0.28 & 51,62 & 1,4 \\
7 & 475,002 & 19.8 & 130,138 & 0.27 & 48,41 & 1 \\
8 & 789,399 & 38.1 & 290,071 & 0.37 & 54,34 & 1,1 \\
9 & $1,170,596$ & 93.3 & 650,385 & 0.56 & 44,46 & 1 \\
10 & 721,109 & 35.0 & 287,471 & 0.40 & 1,1 & 1 \\
\hline
\end{tabular}

${ }^{\mathrm{a}}$ The $x$ and $y$ wind speeds are oriented in the east-west and north-south directions, respectively.

Nevertheless, the scatter due to orientation increases with range for these two locations as well.

\subsection{Effect Of Imposed Errors}

[30] To study the effects of random and systematic radar measurement errors when combined with orientation and range effects, we impose noise on reflectivities measured by the radar simulator. It is a well-established fact from disdrometer studies that there is no unique relationship between rainwater mixing ratio $(M)$ and radar reflectivity (Z). Steiner and Smith [2000] conducted an exhaustive study of 2 years of disdrometer data at Goodwin Creek, where they reported larger anomalies in the $Z-R$ relationship. They found that the uncertainty in the $Z-R$ relationship due to 1-min raindrop spectra variability was approximately $40-50 \%$ as characterized by root-mean-square error. Increasing the time averaging from 1 to $5 \mathrm{~min}$ had little effect on the raindrop spectra variability. We add a normally distributed random error, $N(0,1)$ (i.e., with a mean of 0 and a standard deviation of $1 \mathrm{dBZ}$ ), to the radar reflectivity estimates, which are based on a unique relationship between $Z$ and $M$, to account for the randomness in the $Z-M$ relationship. The $\pm 3 \mathrm{dBZ}$ range of this error agrees with
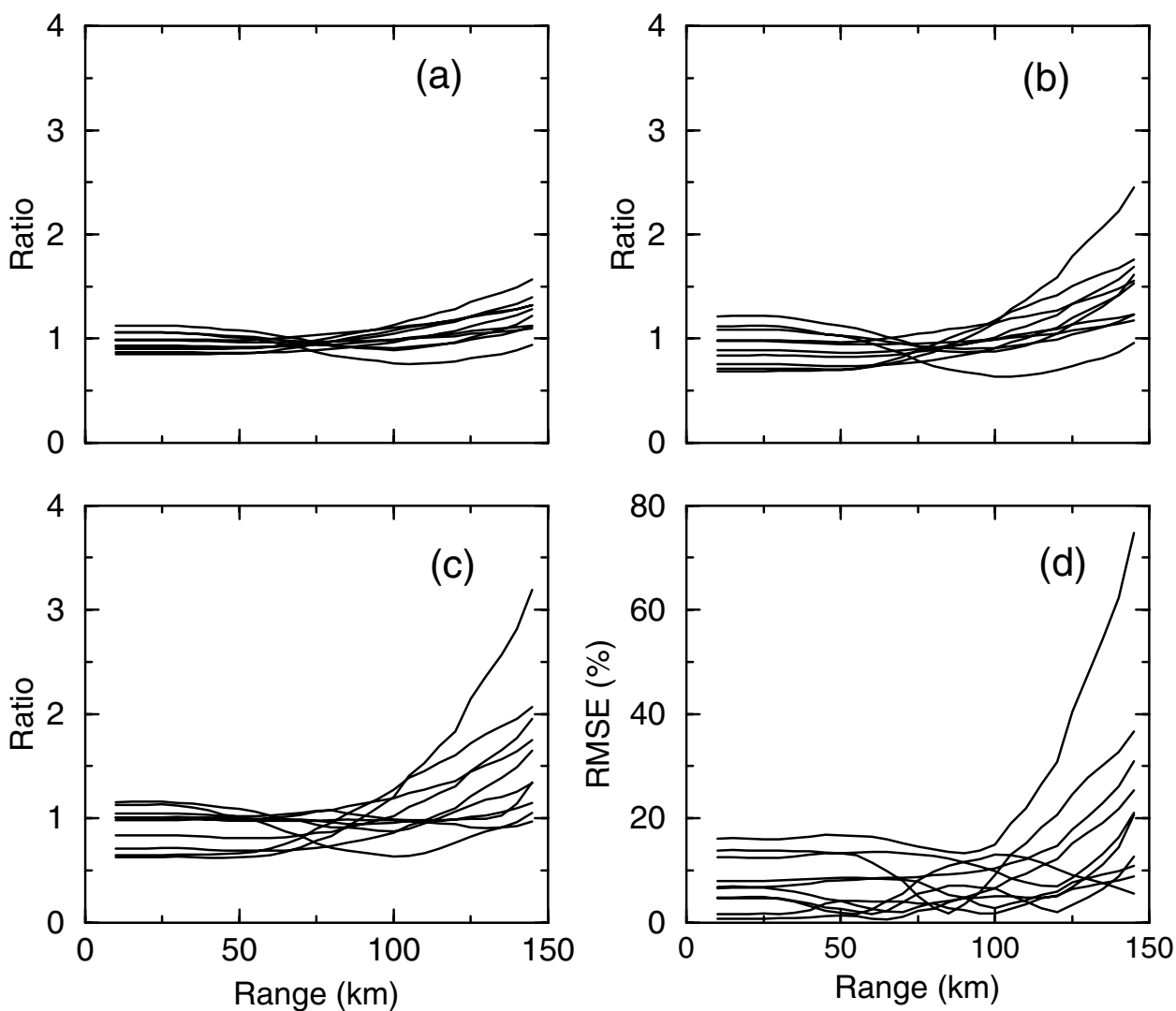

Figure 6. Average of the 24 orientations for the measures shown in Figure 4. Each curve corresponds to a different watershed location in Table 1. 

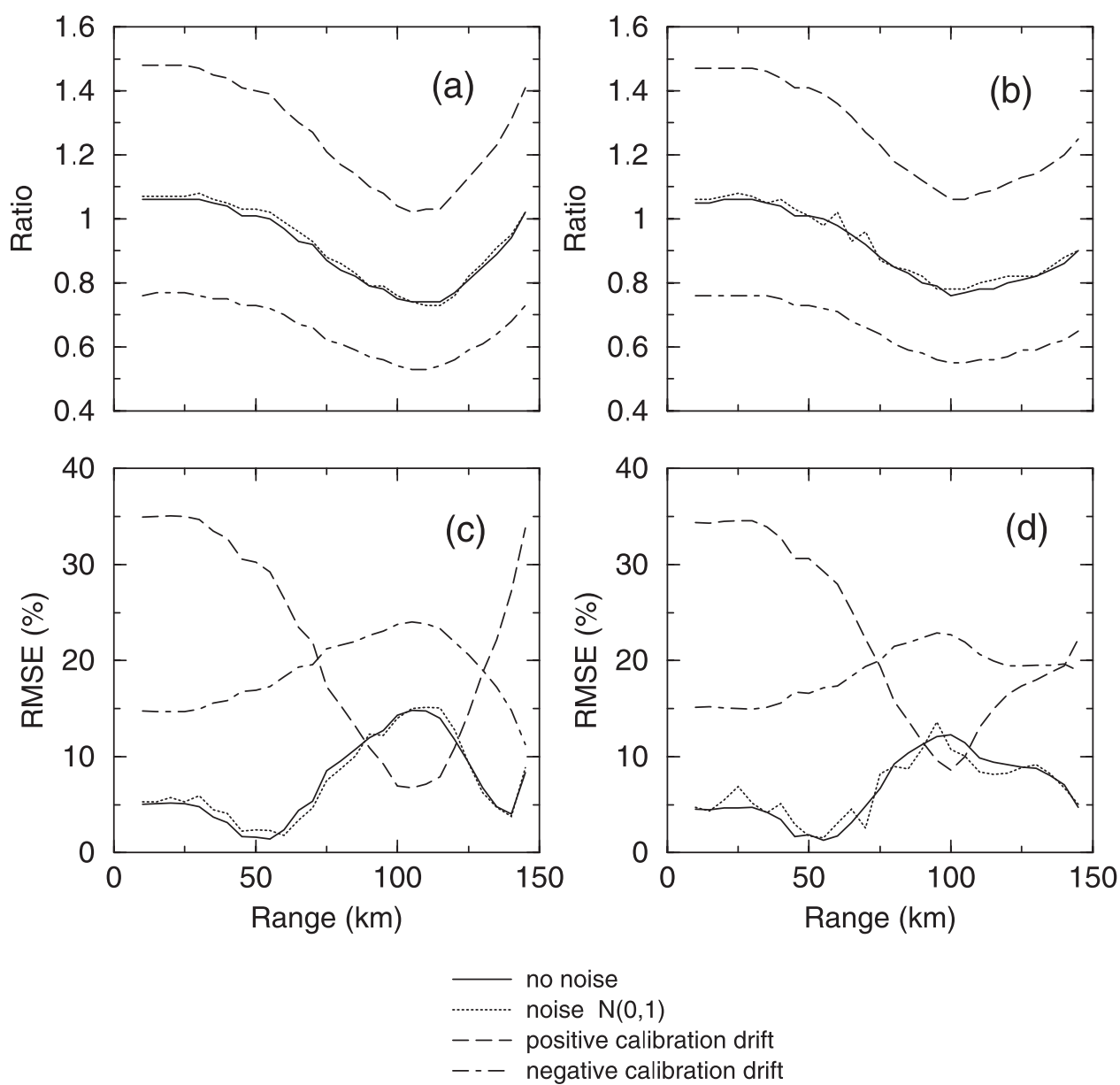

Figure 7. Effects of random and calibration noise on radar-estimated rainfall volume for two radar orientations: (a) orientation 5 and (b) orientation 11 for watershed location 3 in Table 1 . The effects on hydrograph root-mean-square error are shown in Figures $7 \mathrm{c}$ and $7 \mathrm{~d}$ for the same orientations, respectively. Note that positive calibration drift improves rainfall and runoff estimates in Figures $7 \mathrm{~b}$ and $7 \mathrm{~d}$ at far ranges.

the values reported in several studies [e.g., Steiner and Smith, 2000]. This $N(0,1)$ noise can also account for random noise in radar system measurement, such as from a transmitter, receiver, antenna, waveguide, or signal processing error, that corrupts the measurement process.

[31] The radar equation relates radar-measured power to characteristics of the radar and characteristics of the precipitation targets. Doviak and Zrnic [1993]. Smith et al. [1996b] argue that radar calibration, which is dependent on the value of the constant of the radar equation, plays an important role in site-to-site differences in WSR-88D precipitation estimates. Hunter [1996] reports that drifts in absolute radar calibration cause differences of more than $17 \%$ at the same location from adjacent WSR-88Ds. We evaluate the effect of radar calibration errors (drifts) in two additional simulations: A calibration error (drift) of $2 \mathrm{dBZ}$ is added to radar reflectivity measurements in one simulation and is subtracted in another. We select these systematic and random errors as examples of the many errors associated with the radar measurement process to determine their impact on hydrologic predictions.

[32] We show the impact of the imposed errors on estimated predicted rainfall volume error and hydrograph RMSE in Figures $7 \mathrm{a}-7 \mathrm{~d}$. These results are for two different orientations at the same location that we presented in Figure 4. Random noise from the $M-Z$ relationship, or radar system measurement noise, has a small impact on error statistics; it generally decreases the smoothness of individual lines.

[33] The impact of the calibration error alone on the estimated rainfall can be easily quantified by adding the amount of drift (dBZ) to the measured $Z$ value. The effect is different when combined with range/orientation. Calibration error effects can either amplify or reduce range/orientation error. This is especially clear in hydrograph RMSE curves. In some cases, estimates of rainfall volume with imposed calibration errors are better than error-free estimates at far ranges. This is a clear example of the difficult task of trying to isolate separate radar error sources. Radar calibration errors have large effects on all three simulated runoff error statistics.

\subsection{Effect Of Nonuniform Refractive Index}

[34] In all simulated runs the gradient of refractive index has a constant value of -0.0000393 . In one simulation run we calculated the gradient of the refractive index at each grid of the atmospheric model, using the equation relating the refractive index to atmospheric variables [e.g., Battan, 

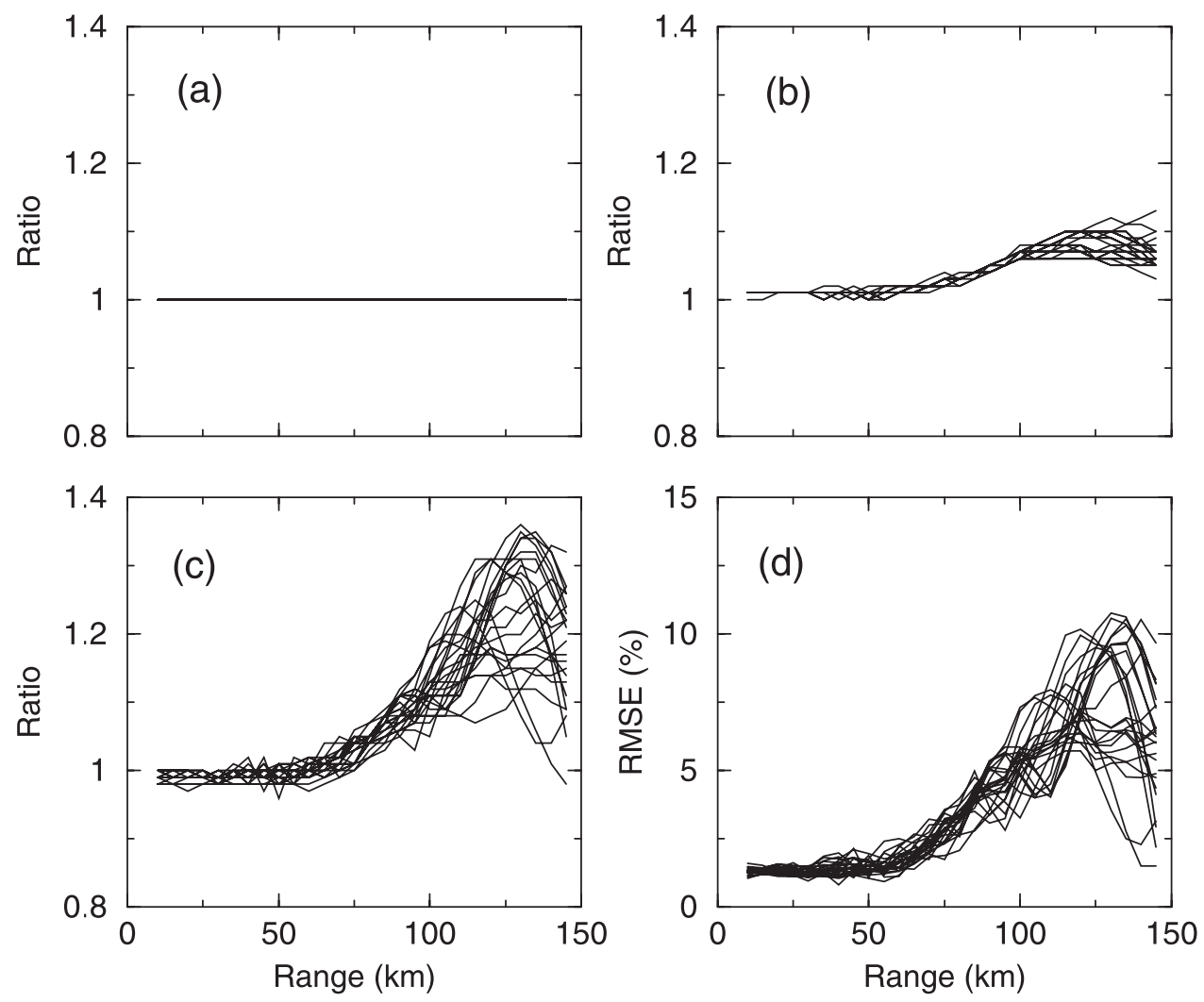

Figure 8. The same measures in Figure 4 after the radar-estimated rainfall volume has been made to be equal to the true rainfall volume for all ranges and orientations by multiplying by a bias factor.

1973]. We then calculated the effect on the path of the propagated radar beam and hence the effect on radar rainfall estimates. When the values of refractive index gradient, which were computed at each atmospheric model grid cell, were used, hydrologic predictions were not significantly affected. In all simulations the terrain is assumed to be perfectly flat and problems of anomalous propagation are not addressed.

\subsection{Adjustment Of Radar Estimates}

[35] Radar rainfall estimation bias can be computed by comparing total radar rainfall accumulation to total rain gauge accumulation. Several prior studies have used computed radar estimation bias to adjust radar estimates by multiplying the radar rainfall estimates by a factor such that total accumulations are the same [see Smith et al., 1996a]. We adjust the radar-estimated rainfall accumulations to match the ARPS rainfall accumulations on a storm total basis in order to examine hydrologic model performance using the adjusted radar rainfall fields as input. We multiply radar estimates by the bias factor such that radar-estimated rainfall volumes are equal to the true rainfall volume. We did this for all ranges and orientations for the radar location analyzed in Figure 4. We find that the predicted runoff volume is practically the same as the reference runoff volume, with small scatter, up to a range of about $70 \mathrm{~km}$. The error in predicted runoff volume increases steadily with an increase in the scatter, as shown in Figure 8b, for ranges beyond $70 \mathrm{~km}$. The runoff volume error when using adjusted radar estimates can reach up to $14 \%$ at $145-\mathrm{km}$ range for some orientations. The error in peak discharge is larger than the error in runoff volume, and the scatter increases appreciably at ranges beyond about $90 \mathrm{~km}$. The maximum error for some simulations is close to $35 \%$, at 125 $\mathrm{km}$. The hydrograph RMSE graph is similar to the peak discharge error graph with a maximum of about $11 \%$ of the peak discharge.

[36] This is just an illustration of the error in predicted hydrograph that can be expected even if radar estimates are bias corrected on a storm total basis. The limitations of this approach have been demonstrated in several previous studies, and we are stressing here that storm total volume adjustments do not adequately address range and orientation effects in hydrologic modeling. Comparing Figure 4 and Figure 8 shows the effect of radar adjustment. Note that in this study we assume that perfect storm total rainfall volume adjustment is possible. In reality, this does not occur. For example, multisensor precipitation estimates [Krajewski, 1987; Seo, 1998] are obtained by adjusting radar estimates using rain gauge data. Consideration of other error sources associated with real multisensor adjustments is beyond the scope of this paper.

\subsection{ARPS Model Resolution Effects}

[37] The atmospheric model grid size, $1.0 \mathrm{~km}$ horizontal and $0.5 \mathrm{~km}$ vertical, is a factor in determining the values of the computed range/orientation errors, but it is not the main cause of the errors. We investigate this using output from two additional ARPS simulations of the same storm with higherresolution outputs: $0.5 \mathrm{~km}$ horizontal and $0.5 \mathrm{~km}$ vertical, and $0.25 \mathrm{~km}$ horizontal and $0.25 \mathrm{~km}$ vertical. Simulations 
(a)

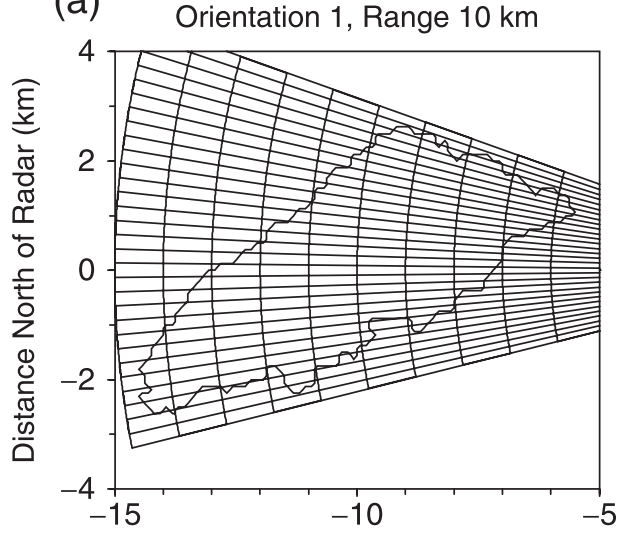

(c)

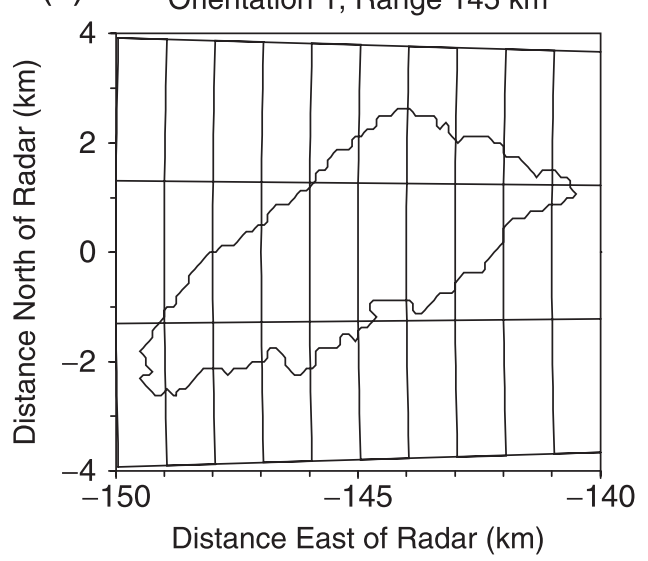

(b)

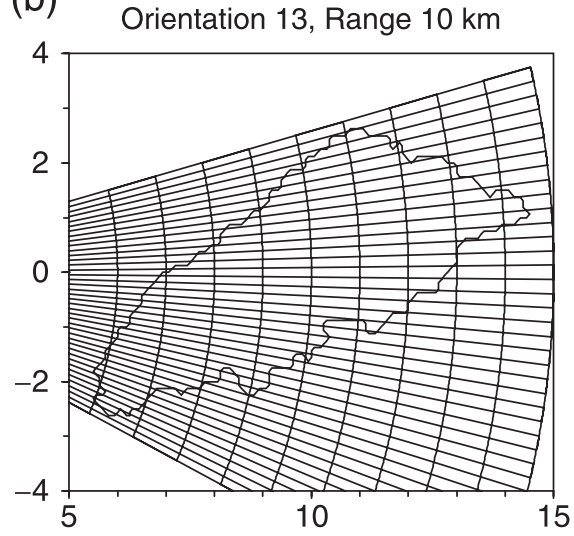

(d)

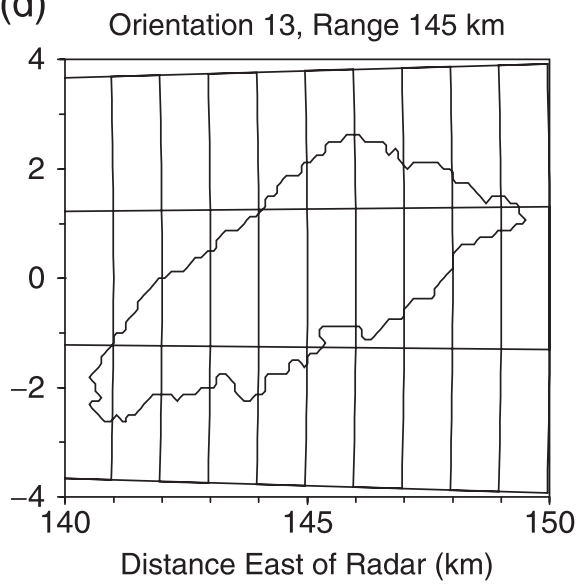

Figure 9. Locations of radar pulse centers for orientations 1 and 13 of Figure 3: (a) orientation 1 at a range of $10 \mathrm{~km}$; (b) orientation 13 at a range of $10 \mathrm{~km}$; (c) orientation 1 at a range of $145 \mathrm{~km}$; and (d) orientation 13 at a range of $145 \mathrm{~km}$.

with these finer-resolution three-dimensional atmospheric fields showed no reduction in the average radar range/ orientation errors. There are minor differences between the results of the two higher-resolution simulations, which demonstrate that for this storm there is no practical accuracy gained for resolutions higher than $0.5 \times 0.5 \times 0.5 \mathrm{~km}$.

[38] Rainwater mixing ratios have discrete values in each ARPS grid. To further assess the impact of the discrete nature of the ARPS output, we use simulated radar observations of continuous, hypothetical rainfall fields. The variations between rainwater mixing ratios are assumed to be continuous (not discrete) within the simulated domain, which covers a rectangle of $7 \times 10 \mathrm{~km}$. The vertical profile of rainwater mixing ratios follows a general extreme value (GEV) distribution $(1.0,1.0,-0.1), f_{1}(z)$, where the $x$ axis variation follows a Gumbel distribution $\mathrm{G}(19.0,3.0), f_{2}(x)$, and the $y$ axis variation follows a Gumbel distribution $\mathrm{G}(15.0,4.5), f_{3}(y)$. At every point, $p(x, y, z)$, the rainwater mixing ratio $M$ is calculated by the relationship $M=f_{1}(z) \times$ $f_{2}(x) \times f_{3}(y) \times 0.625 \mathrm{~kg} \mathrm{~m}^{-3}$. We admit that these are not realistic rainfall fields, since no real storm can be so smooth. They are only meant to serve as illustrative examples of the measurement errors under consideration. Note that the vertical profile of reflectivity is a function of $z$ only and does not vary horizontally. The rainfall rate at ground level is irrelevant in this portion of our study because our purpose is solely to examine the effect of the interaction of radar beam geometry and orientation on radar rainfall estimates using continuous $M$ fields. Radar rainfall estimates of these simulated fields have range/orientation errors, which increase with range. Errors are also amplified in the predicted runoff. Real storms, like the Del City storm, show significant randomness in horizontal and vertical variability, which also contributes to the range/orientation effects.

[39] A closer look at the geometry of the radar pulse volume, beam propagation path, elevation, and azimuthal angle reveals some of the aspects of the range/orientation effects. For two radars at orientations $180^{\circ}$ apart, the sampling volume is almost identical when the beams are concentric and the same distance away from the two radars at near ranges, particularly if they are on the line that connects the two radars. Sampling volumes that are on the straight line between the two radars are still very similar at close ranges, but the difference increases with increasing range. At points not on this line and at different distances from the two radars, there can be significant differences in the size, height, and orientation of the sampling volumes, resulting in large differences in radar estimates. This can be illustrated by considering the differences between radar rainfall estimates at orientation 1 and orientation 13, as shown in Figure 3. To ensure that grid size does not cause these discrepancies, we analyze the case of the hypothetical rainfall fields mentioned above. In Figure 9 we show the locations of radar pulse volume centers within the rectangle that encompasses the 
watershed for the two radars at ranges of 10 and $145 \mathrm{~km}$. We compute the differences between the radar estimates at each location. At the smallest practical range we are considering, the differences are negligible at the center where the two beams are almost concentric and at equal distance from the two radars. On the line perpendicular to the line connecting the two radars, where the beams are not exactly concentric but approximately at equal distance from the two radars and at the same height, the maximum difference in point estimates of rainfall rate is about $1 \%$ on the edges of the rectangle. On the line connecting the two radars the maximum difference at the edges of the rectangle is $3 \%$. At the corners of the rectangle it is about $4 \%$. The difference in estimated total rainfall volume is about $1 \%$.

[40] The picture is quite different at the $120-\mathrm{km}$ range. At the center of the watershed the difference is $3 \%$. This is due to differences in the sampling volume between the two radar beams. The differences on the edges of the perpendicular line are $9 \%$. On the line between the two radars the maximum difference is $10 \%$, and the difference in total estimated rainfall volume on the watershed is $6 \%$. This is an illustration of the range/orientation effect, and the numbers are a sample of these errors. Note that in the above analysis, the vertical profile of the rainwater mixing ratio does not vary horizontally.

[41] The azimuthal resolution is one of the factors that controls the orientation effect. In a test run, where we changed the azimuthal resolution from $1^{\circ}$ to $0.3^{\circ}$ by oversampling, the scatter at far ranges was reduced by about $30 \%$. Reducing the radar beam width results in similar reduction in orientation effects.

[42] The choice of the $Z-R$ relationship in this study is arbitrary. Our simulations show that small changes to the $Z-R$ relationship parameters have no significant effects on the hydrologic outputs; for example, changing the multiplicative coefficient from 300 to 400, and the power coefficient from 1.4 to 1.3 , changes the outputs by less than $5 \%$.

\section{Discussion}

[43] The propagation of the radar beam is accompanied by an increase in the radar sampling volume and an increase of the height of the radar beam center, with range depending on elevation angle and Earth curvature. The gradient of the atmospheric refraction index also affects the path of electromagnetic waves through the rainy atmosphere. These two factors, i.e., increase in volume and increase in height, cause several errors (e.g., smoothing of reflectivity gradient and overshooting of precipitation) and also play a role in the presence of the orientation effect, which increases with range.

[44] All the simulations in this study highlight the range/ orientation effects for convective storms and their propagation through hydrologic model predictions for a $21 \mathrm{~km}^{2}$ watershed. It is well known that other factors in the radar rainfall measurement/estimation process can cause errors larger than the errors we discuss here. However, pinpointing and quantifying these errors provide incentives to study these errors and search for means to adjust them. We do not think that these simulations, which demonstrate examples of the impact of high variability within convective cells, present worst-case scenarios in small-sized watersheds. We have chosen error statistics at the watershed scale (e.g., we did not consider errors in instantaneous values of variables at the pulse volume scale). For larger watersheds, there might be similar range/orientation errors, at least at smaller temporal or spatial scales. For example, Ogden and Julien [1994] found that the effect of radar data resolution depended upon "storm smearing" and "watershed smearing." Storm smearing occurs when the radar rainfall data resolution is coarser than the rainfall spatial correlation length. Storm smearing reduces rainfall gradients and is independent of the watershed size. Watershed smearing occurs when the radar rainfall data resolution exceeds $40 \%$ of the square root of the watershed area, creating uncertainty with regard to the location of precipitation relative to the watershed boundary. Watershed smearing is the main source of hydrologic model error in very small subcatchments. For the $21 \mathrm{~km}^{2}$ Goodwin Creek watershed used in our study, storm smearing is the dominant error source at intermediate ranges studies, while watershed and storm smearing are both factors at far ranges.

\section{Summary and Conclusions}

[45] We developed a simulation framework for the study of the hydrological impacts of radar rainfall estimation errors. The simulation framework is physically based and consists of an atmospheric model, a simulator of radar observations, and a distributed hydrologic model. The storm we used in our study is well documented and is considered a benchmark storm for the validation of atmospheric models (see ARPS references). The rainfall fields we simulated in this study are adequately realistic and can serve as an example of supercell storms that cause flash flooding in small- and medium-sized watersheds. Although we use only single-polarization radar reflectivity in this study, the radar data simulator has the capability to generate multiparameter radar observables (e.g., differential reflectivity and differential propagation phase shift). Using our approach, it is possible to simulate several sources of radar measurement and estimation errors, both systematic and random.

[46] The distributed physically based hydrologic model CASC2D [Julien et al., 1995; Ogden, 1998] we use in the study is rigorously calibrated [Senarath et al., 2000] on an extensively monitored research watershed. This leads us to believe that the propagated errors in predicted runoff provide examples of what to expect in real-world hydrologic studies using a physically based, distributed, Hortonian model.

[47] Range effects are caused primarily by the vertical profile of reflectivity and the size of the radar pulse volume. The differences in radar predictions caused by the orientation between the radar, the storm, and the watershed (see Figure $4 \mathrm{a}$ for an example) depend mainly on the size of the pulse volume and the sampling resolution. Though it is not practically feasible, two identical radars at two different orientations could hypothetically give identical measurements of a storm, if there were no vertical variability and the radar pulse volume and the azimuthal resolution is were small enough to capture the horizontal variability, and if we were to neglect attenuation effects. The actual difference between the two estimates depends on the radar pulse volume, the azimuthal resolution, and the vertical and horizontal variability within the storm, among other factors. Decreasing the azimuthal resolution can remove a large portion of the orientation effects. Measurements by two or 
more radars of the same storms were discussed in several radar rainfall estimation studies [e.g., Smith et al., 1996b; Ogden et al., 2000] and in studies of radar data assimilation [e.g., Sun et al., 1991; Sun and Crook, 1998]. The orientation effects we investigate give rise to many interesting questions: Do the radar estimation/measurement errors cancel each other out? Does the mosaicking of the multiple radar data help reduce errors? Does a miscalibrated radar always give inferior estimates compared with a well-calibrated one?

[48] Hydrologic simulations demonstrate that range and orientation errors are typically amplified through predicted Hortonian runoff. In many cases, errors in runoff are nearly twice the magnitude of rainfall volume errors. Amplification of errors is larger at locations of small total rainfall volume.

[49] Computing the actual values of the gradient of the atmospheric refractive index (as opposed to assuming a constant value) does not affect hydrologic model predictions, provided that anomalous propagation does not occur. Random noises that corrupt the radar measurement process, at least those considered in this study, have minor hydrologic impacts compared with the systematic range effects. Calibration errors can have a significant impact on predicted runoff.

[50] At far ranges, radar measurements corrupted by calibration errors sometimes result in more accurate hydrologic model predictions than error-free measurements (Figure 7). This makes identifying radar measurement errors more complicated and may lead to erroneous conclusions when radar measurements are compared with the measurements of other sensors.

[51] Adjustment of radar rainfall estimates by multiplying them by a bias factor to make the total rainfall volume match the "true" rainfall volume, as done in multisensor estimates, seems to provide acceptable runoff volume and hydrograph predictions at radar ranges below $100 \mathrm{~km}$. At farther ranges the runoff predictions have appreciable errors, despite storm total rainfall bias correction.

[52] The simulation framework we present in this paper provides a useful tool for studying the problems of the hydrologic applications of weather radar data. In particular, we focus on the issue of radar rainfall estimation uncertainty and the propagation of the errors through rainfall runoff models. Our study admittedly has limitations. We only consider a single, convective storm and neglect the effect of bright band. We do not address the issues of radar data quality control (such as anomalous echo detection and elimination). We only consider single-parameter S-band radars. Still, despite these and other limitations, we demonstrate the utility of the simulation approach and consider the insight it provides. For example, we study the nonnegligible effects of radar position (orientation) with respect to the basin, and we are able to isolate the quantitative effects of various radar-related sources of uncertainty. The significant level of some of these effects clearly indicates the need for more research on these issues. Such studies should include both simulation methods, such as the one we describe above, as well as data-based studies. We hope that through collaboration between the relevant federal agencies and the research community we will be able to design and conduct appropriate field and data experiments. We believe that such experiments will ultimately lead to improved hydrologic predictions.
[53] Acknowledgments. The authors acknowledge the assistance of Emmanouil "Manos" Anagnostou of the University of Connecticut in adapting the radar simulator to function with ARPS output. This project was primarily funded by the U.S. Army Research Office through Young Investigator grant DAAH04-96-1-0026 to the second author with a subcontract to the Iowa Institute of Hydraulic Research.

\section{References}

Alonso, C. V., Hydrologic research on the USDA Goodwin Creek Experimental Watershed, northern Mississippi, in Proceedings of the 16th Annual AGU Hydrology Days Conference, pp. 25-36, Hydrol. Days Publ., Atherton, Calif., 1996.

Anagnostou, E. N., and W. F. Krajewski, Simulation of radar reflectivity fields: Algorithm formulation and evaluation, Water Resour. Res., 33(6), 1419-1429, 1997

Anagnostou, E. N., and C. A. Morales, TRMM precipitation radar helps address problems of ground-based weather radar systems, Eos Trans $A G U, 81(44), 513,2000$.

Austin, P. M., Relation between radar reflectivity and surface rainfall, Mon Weather Rev., 115(5), 1053-1070, 1987

Barge, B. L., R. G. Humphries, S. J. Mah, and W. K. Kuhnke, Rainfall measurements by weather radar: Applications to hydrology, Water Resour. Res., 15(6), 1380-1386, 1979.

Battan, L. J., Radar Observation of the Atmosphere, Univ. of Chicago Press, Chicago, Ill., 1973.

Bingner, R. L., Runoff simulated from Goodwin Creek watershed using SWAT, Trans. ASAE, 39, 85-90, 1996.

Brazil, L. E., Multilevel calibration strategy for complex hydrologic models, Ph.D. dissertation, 192 pp., Colo. State Univ., Fort Collins, 1988.

Calheiros, R. V., Local effects on climatological $\mathrm{Z}_{\mathrm{h}}-\mathrm{R}$ relationships, in Proceedings of the 22nd Conference on Radar Meteorology, pp. $341-$ 345, Am. Meteorol. Soc., Boston, Mass., 1984.

Ciach, G. J., and W. F. Krajewski, On the estimation of radar rainfall error variance, Adv. Water Resour., 22, 585-595, 1999.

Doviak, R. J., and D. S. Zrnic, Doppler Radar and Weather Observations, Academic, San Diego, Calif., 1993

Downer, C. W., F. L. Ogden, W. Martin, and R. S. Harmon, Theory, development and applicability of the surface water hydrologic model CASC2D, Hydrol. Processes, 16(2), 255-275, 2002.

Droegemeier, K. K., et al., The 1996 CAPS spring operational forecasting period: Real-time storm-scale NWP, part I, Goals and methodology, in Preprints of the 11th Conference on Numerical Weather Prediction, pp. 294-296, Am. Meteorol. Soc., Boston, Mass., 1996.

Fulton, R. A., J. P. Breidenbach, D.-J. Seo, and D. A. Miller, WSR-88D rainfall algorithm, Weather Forecasting, 13, 377-395, 1998.

Gao, J., M. Xue, Z. Wang, and K. K. Droegemeier, The initial condition and explicit prediction of convection using ARPS adjoint and other retrieval methods with WSR-88D data, in Proceedings of the 12th Conference on Numerical Weather Prediction, pp. 176-178, Am. Meteorol. Soc., Boston, Mass., 1998.

Georgakakos, K. P., A generalized stochastic hydrometeorological model for flood and flash flood forecasting, 1, Formulation, Water Resour. Res., 22(13), 2083-2095, 1986a.

Georgakakos, K. P., A generalized stochastic hydrometeorological model for flood and flash flood forecasting, 2, Case studies, Water Resour. Res., 22(13), 2096-2106, 1986b.

Grecu, M., and W. F. Krajewski, Rainfall forecasting using variational assimilation of radar data in numerical cloud models, Adv. Water Resour., 24(2), 213-224, 2000a

Grecu, M., and W. F. Krajewski, A large-sample investigation of statistical procedures for radar-based short-term quantitative precipitation forecasting, J. Hydrol., 239(1-4), 69-84, 2000b.

Green, W. H., and G. A. Ampt, Studies on soil physics, 1, Flow of air and water through soils, J. Agric. Sci., 4, 1-24, 1911.

Horton, R. E., The role of infiltration in the hydrologic cycle, Eos Trans. $A G U, 14,446-460,1933$.

Hunter, S., WSR-88D radar rainfall estimation: Capabilities, limitations and potential improvements, Natl. Weather Dig., 20(4), 26-36, 1996.

Julien, P. Y., and G. E. Moglen, Similarity and length scale for spatially varied overland flow, Water Resour. Res., 26(8), 1819-1832, 1990.

Julien, P. Y., B. Saghafian, and F. L. Ogden, Raster-based hydrologic modeling of spatially varied surface runoff, Water Resour. Bull., 31(3), 523535,1995

Kessler, E., On the distribution and continuity of water substance in atmospheric circulation, Meteorol. Monogr., 10, 84 pp., 1969. 
Klemp, J. B., R. B. Wilhelmson, and P. S. Ray, Observed and numerically simulated structure of a mature supercell thunderstorm, J. Atmos. Sci., $38,1558-1580,1981$.

Krajewski, W. F., Cokriging of radar rainfall and rain gauge data, J. Geophys. Res., 92, 9571-9580, 1987.

Krajewski, W. F., and J. A. Smith, On the estimation of climatological Z-R relationships, J. Appl. Meteorol., 30(10), 1436-1445, 1991

Krajewski, W. F., R. Raghavan, and V. Chandrasekar, Physically based simulation of radar rainfall data using a space time rainfall model, $J$ Appl. Meteorol., 32(2), 268-283, 1993.

Kummerow, C., W. Barnes, T. Kozu, J. Shiue, and J. Simpson, The tropical rainfall measuring mission (TRMM) sensor package, J. Atmos. Oceanic Technol., 15, 808-816, 1998.

Lin, Y., P. S. Ray, and K. W. Johnson, Initialization of a modeled convective storm using Doppler radar-derived fields, Mon. Weather Rev., 121, 2757-2775, 1993

Ogden, F. L., De St. Venant channel routing in distributed hydrologic modeling, paper presented at the Hydraulic Specialty Conference, Am Soc. of Civ. Eng., Buffalo, N. Y., 1-5 Aug, 1994.

Ogden, F. L., CASC2D Version 1.18 Users's Manual, Dep. of Civ. and Environ. Eng., Univ. of Conn., Storrs, 1998.

Ogden, F. L., and P. Y. Julien, Runoff model sensitivity to radar rainfall resolution, J. Hydrol., 158, 1-18, 1994.

Ogden, F. L., and B. Saghafian, Green and Ampt infiltration with redistribution, J. Irrig. Drain. Eng., 123(5), 386-393, 1997.

Ogden, F. L., and S. U. S. Senarath, Continuous distributed-parameter hydrologic modeling with CASC2D, in Proceedings of the XXVII IAHR Congress, pp. 864-869, Int. Assoc. for Hydraul. Res., Gentbrugge, Belgium, 1997.

Ogden, F. L., and H. O. Sharif, Rainfall input for distributed hydrologic modeling-The case for radar, in Proceedings of ASCE Watershed Management Conference, CD-ROM,, Am. Soc. of Civ. Eng., Reston, Va., June 2000

Ogden, F. L., H. O. Sharif, S. U. S. Senarath, J. A. Smith, M. L. Baeck, and J. R. Richardson, Hydrologic analysis of the Fort Collins, Colorado, flash flood of 1997, J. Hydrol., 228, 82-100, 2000.

Ray, P. S., B. Johnson, K. W. Johnson, J. S. Bradberry, J. J. Stephens, K. K. Wagner, R. B. Wilhelmson, and J. B. Klemp, The morphology of severe tornadic storms on 20 May 1977, J. Atmos. Sci., 38, 1643-1663, 1981

Senarath, S. U. S., F. L. Ogden, C. W. Downer, and H. O. Sharif, On the calibration and verification of distributed, physically based, continuous, Hortonian hydrologic models, Water Resour. Res., 36(6), 1495-1510, 2000.

Seo, D.-J., Real-time estimation of rainfall fields using radar rainfall and rain gage data, J. Hydrol., 208, 37-52, 1998

Shapiro, A., L. Zhao, S. Weygandt, K. Brewster, S. Lazarus, and K. K. Droegemeier, Initial forecast fields from single-Doppler wind retrieval, thermodynamic retrieval and ADAS, in Preprints of the 11th Conference on Numerical Weather Prediction, pp. 119-121, Am. Meteorol. Soc., Boston, Mass., 1996.

Smith, J. A., and W. F. Krajewski, A modeling study of rainfall rate-reflectivity relationships, Water Resour. Res., 29(8), 2505-2514, 1993.

Smith, J. A., M. L. Baeck, M. Steiner, and A. J. Miller, Catastrophic rainfall from an upslope thunderstorm in the central Appalachians: The Rapidan storm of June 27, 1995, Water Resour. Res., 32(10), 3099-3113, 1996a.

Smith, J. A., D. J. Seo, M. L. Baeck, and M. D. Hudlow, An intercomparison study of NEXRAD precipitation estimates, Water Resour. Res., 32(7), 2035-2045, 1996b.

Steiner, M., and J. A. Smith, Reflectivity rain rate and kinetic energy flux relationships based on raindrop spectra, J. Appl. Meteorol., 39(11), $1923-1940,2000$
Sun, J., and N. A. Crook, Dynamical and microphysical retrieval from Doppler radar observations using a cloud model and its adjoint, part II, Retrieval experiments of an observed Florida convective storm, J. Atmos. Sci., 55, 835-852, 1998 .

Sun, J., W. Flicker, and D. K. Lilly, Recovery of three-dimensional wind and temperature fields from simulated single-Doppler data, J. Atmos. Sci., 48, 876-890, 1991

Szoke, E. J., E. J. Zipser, and D. P. Jorgensen, A radar study of convective cells in mesoscale systems in GATE, part I, Vertical profile statistics and comparison with hurricanes, J. Atmos. Sci., 43, 132-197, 1986a.

Szoke, E. J., E. J. Zipser, and D. P. Jorgensen, A radar study of convective cells in mesoscale systems in GATE, part II, Life cycles of convective cells, J. Atmos. Sci., 43, 199-218, 1986b.

Vignal, B., and W. F. Krajewski, Large sample evaluation of two methods to correct range-dependent error for WSR-88D rainfall estimates, J. Hydrometeorol., 2(5), 490-504, 2001.

Wilson, J. W., and E. A. Brandes, Radar measurement of rainfall-A summary, Bull. Am. Meteorol. Soc., 60(9), 1048-1058, 1979.

Xue, M., K. K. Droegemeier, V. Wong, A. Shapiro, and K. Brewster, ARPS Version 4.0 User's Guide, 380 pp., Cent. for Anal. and Predict. of Storms, Univ. of Okla., Norman, 1995.

Xue, M., K. Brewster, K. K. Droegemeier, F. Carr, V. Wong, Y. Liu, A. Sathye, G. Bassett, P. Janish, J. Levit, and P. Bothwell, Real-time numerical prediction of storm-scale weather during VORTEX-95, part II, Operation summary and example cases, in Preprints, 18th Conference on Severe Local Storms, pp. 178-182, Am. Meteorol. Soc., Boston, Mass., 1996a.

Xue, M., K. Brewster, K. K. Droegemeier, V. Wong, D. H. Wang, F. Carr, A. Shapiro, L. M. Zhao, S. Weygandt, D. Andra, and P. Janish, The 1996 CAPS spring operational forecasting period: Real-time storm-scale NWP, part II, Operational summary and examples in Preprints, 11th Conference on Numerical Weather Prediction, pp. 297-300, Am. Meteorol. Soc. Boston, Mass., 1996b.

Xue, M., K. K. Droegemeier, and V. Wong, The Advanced Regional Prediction System (ARPS)-A multiscale nonhydrostatic atmospheric simulation and prediction tool, part I, Model dynamics and verification, Meteorol. Atmos. Phys., 75, 161-193, 2000.

Xue, M., K. K. Droegemeier, V. Wong, A. Shapiro, K. Brewster, F. Carr, D. Weber, Y. Liu, and D.-H. Wang, The Advanced Regional Prediction System (ARPS)-A multiscale nonhydrostatic atmospheric simulation and prediction tool, part II, Model physics and applications, Meteorol. Atmos. Phys., 76, 143-165, 2001.

Zawadzki, I., On radar-rain gauge comparison, J. Appl. Meteorol., 14, $1430-1436,1975$

Zawadzki, I., The quantitative interpretation of weather radar measurement, Atmos. Ocean, 20, 158-180, 1982.

Zawadzki, I., Factors affecting the precision of radar measurement of rainfall, in Proceedings of the 22nd Conference on Radar Meteorology, pp. 251-256, Am. Meteorol. Soc., Boston, Mass., 1984.

W. F. Krajewski, IIHR/Hydroscience and Engineering, University of Iowa, Iowa City, IA 52242, USA.

F. L. Ogden, Department of Civil and Environmental Engineering, U-37, University of Connecticut, Storrs, CT 06269, USA.

H. Sharif, National Center for Atmospheric Research, Research Applications Program, P.O. Box 3000, Boulder, CO 80307-3000, USA. (sharif@ucar.edu).

M. Xue, Center for Analysis and Prediction of Storms, University of Oklahoma, Norman, OK 73019, USA. 